\title{
Vorwort zu Band 5
}

Theologie äußert sich auf verschiedene Weise. Im Aufsatz lässt sie an der Forschung teilhaben, im Buch fasst sie Forschungsergebnisse zusammen, in der Vorlesung formuliert sie die Lehre in den unterschiedlichen Fächern. Eine ganz eigene Form der theologischen Äußerung ist die Predigt. Sie gibt die biblische Botschaft an die Gemeinde weiter. In der Predigt spricht sich die Theologie von ihren schulmäßigen Voraussetzungen frei und spricht den Menschen, die zuhören, Gottes Wort, seine Verheißung und sein Gebot, sein Urteil und seinen Trost zu.

In diesem Sinn hat Hans Joachim Iwand gepredigt.

Wir legen hier eine weitere Auswahl seiner Predigten vor. Ein erster Band erschien 1963 in der Reihe der Nachgelassenen Werke. In der Neuen Folge werden bisher unveröffentlichte Predigten zugänglich gemacht, im Anhang verstreut veröffentlichte, heute eher unzugängliche Texte. Den Gattungsbegriff "Predigt" legen wir dabei nicht eng aus, auch sogenannte Bibelarbeiten und Andachten sind in den Band aufgenommen, dazu das Fragment einer Homiletik-Vorlesung, die Iwand in einem Predigerseminar der Bekennenden Kirche hielt. Es gibt zum Band 3 der Nachgelassenen Werke eine einzige Überschneidung: die erste Predigt der Hiobreihe, die wir um der Vollständigkeit der Reihe willen nicht auslassen wollten.

Über Einzelheiten der Predigtinhalte, der Textüberlieferung und der biografischen Einordnung geben die Nachworte Auskunft.

Den Predigten sind die Predigttexte jeweils vorangestellt, Zitate daraus in der Predigt kursiv kenntlich gemacht. Die einzige Ausnahme sind die langen Hiobkapitel, die wir die Leserinnen und Leser in der Bibel nachzulesen bitten. In der Regel folgen die Bibeltexte der Revision der Lutherbibel von 1912, die Iwand benutzte; seltene Ausnahmen sind eigene Übersetzungen Iwands.

Ostern 2004

Albrecht Grözinger

Bertold Klappert

Rudolf Landau

Jürgen Seim 
